\title{
Resiliência de idosos institucionalizados participantes de um programa com jogos
}

\section{Resilience institutionalized elderly participants of a program with games}

Clécia Rodrigues Fernandes Ribeiro

Mileyde Bárbara Santos Guedes²

José Maurício Figueiredo Júnior $r^{1,3}$

Pierre Normando Gomes-da-Silva ${ }^{2}$

\section{RESUMO}

Essa pesquisa teve como objetivo analisar a capacidade de resiliência em idosos residentes numa instituição de longa permanência que participaram de um programa de práticas corporais com jogos. Utilizou-se da abordagem qualitativa para coletar as informações a partir da observação participante, a fim de analisar as falas de 25 idosos coletadas no final de cada intervenção com jogos (Passa bola, Boliche e Bocha) durante o Círculo de Cultura. Por meio da análise de conteúdo organizamos as falas em três categorias: Perseverança, Superação e Bem-estar. Constatou-se a presença de situações promovidas pelo jogo que estimulou o aparecimento dos indicadores para o desenvolvimento da resiliência. Percebe-se que o planejamento de intervenções em instituições de longa permanência deve oportunizar mudanças adaptativas que proporcionem equilíbrio entre ganhos e perdas inerentes ao processo de envelhecimento. Como também, as atividades propostas para idosos institucionalizados devem potencializar o enfrentamento de situações adversas, de modo a emergir os sentimentos de perseverança, superação e bem-estar, considerados indicadores e condicionantes para o desenvolvimento da resiliência. Assim, é necessária uma intervenção bem planejada dos profissionais responsáveis pela atenção aos residentes. Essa intervenção deve prevê metodologias que contemplem atividades, na qual, o idoso seja visto de forma holística, ao contrário de analisá-lo estritamente sob sua condição de saúde física e biológica.

\section{PALAVRAS-CHAVE}

Idoso; Atividade física; Promoção da saúde; Saúde do idoso institucionalizado; Saúde do idoso.

\section{ABSTRACT}

This research aimed to analyze the resilience in elderly residents in long-stay institution that participated in a program of bodily practices with games. We used a qualitative approach to collect information from participant observation in order to analyze the collected speeches of 25 seniors at the end of each intervention with games (Pass Ball, Bowling and Bocce) during the Culture Circle. Through content analysis of the speeches organized into three categories: Perseverance, Resilience and Well-being. It was observed the presence of game situations promoted by the onset of stimulated indicators for the development of resilience. One realizes that the planning of interventions in longterm institutions must create opportunities adaptive changes that provide balance between gains and losses inherent in the aging process. As well, proposals for elderly institutionalized activities should enhance coping with adverse situations in order to emerge the feelings of perseverance, resilience and well-being, considered indicators and constraints to the development of resilience. Thus, a well planned by professionals responsible for care to residents intervention is necessary. Such intervention must provides methodologies that address activities, in which the elderly is viewed holistically, as opposed to analyzing it strictly under its condition of physical and biological bealth.

\section{KEYWORDS}

Aged; Motor Activity; Health Promotion, Health of Institutionalized Elderly; Health of the Elderly.
Rev Bras Ativ Fis Saúde p. 465-474 DOI

http://dx.doi.org/10.12820/rbafs.v.19n4p465

1 Faculdade Maurício de Nassau.

2 Universidade Federal da Paraíba Departamento de Educação Física - João Pessoa

3 Faculdades Integradas de Patos.- Paraíba Brasil. 


\section{INTRODUÇÃO}

Atualmente, com o aumento da expectativa de vida em nível mundial, houve um acréscimo significativo da população que vivencia o processo de envelhecimento. Este pode ser caracterizado como sendo um processo natural do desenvolvimento humano, que acarreta mudanças físicas e morfológicas, as quais se manifestam pela diminuição das funções do organismo ${ }^{1}$.

Nesse contexto, levando-se em consideração as peculiaridades do envelhecer, durante essa fase da vida, o indivíduo passa a requerer várias demandas nas áreas de prestação de serviços, emergindo questões como a responsabilidade do Estado, da sociedade e da família quanto à moradia e o cuidado para com esse indivíduo. Esses questionamentos remetem a uma antiga discussão, a saber, a institucionalização do idoso. Trata-se de uma questão polêmica e complexa, por envolver questões políticas, sociais, econômicas, de saúde e psicoemocionais, além de cunho preconceituoso e moral.

As Instituições de Longa Permanência para Idosos (ILPI), assim denominada, pela Política Nacional do Idoso e pela Sociedade Brasileira de Geriatria e Gerontologia, que vem substituir e unificar os termos asilo, abrigo, casa de repouso, lar, clínica geriátrica, ancianato e similares são reconhecidas e consideradas um espaço de atendimento em regime de internato para idosos sem vínculo familiar ou sem condições de prover sua própria subsistência ${ }^{2}$.

Se as ILPI ou asilos, como conhecidos popularmente, em tempos passados se destinavam à velhice desvalida, na atualidade, com o envelhecimento populacional acentuado, esses locais passam a ter uma nova missão: promover a qualidade de vida do idoso em suas dimensões biopsicossocial ${ }^{3}$.

Segundo alguns autores ${ }^{2,4}$, os motivos mais frequentes que levam o idoso à institucionalização são questões familiares, sobretudo, no que diz respeito ao matrimônio (estado civil solteiro, divórcios, morte do cônjuge), questões financeiras e a convivência simultânea entre várias gerações numa mesma família gerando confronto entre os membros devido à divergência de ideias, valores e comportamentos.

A institucionalização, em grande parte das vezes, requer grande capacidade de adaptação por parte do idoso, pois provoca mudanças em seu estilo de vida, no qual a utilização do tempo é destinada apenas a alimentação, higiene pessoal e repouso, salvo algumas exceções, quando a instituição recebe a atenção de voluntários, geralmente, estudantes de graduação de cursos da área de ciências da saúde, que desenvolvem, ocasionalmente, atividades especializadas ${ }^{5}$. Porém, essas atividades, por serem desenvolvidas por estudantes voluntários, em cumprimento de estágios curriculares, não asseguram a permanência e continuidade das atividades propostas ${ }^{2-4}$.

A participação em atividades diversas no âmbito de ILPI pode constituir um meio significativo para o desenvolvimento do idoso, pois permite vivências relevantes para seu bem-estar como: significado existencial, interação social, motivação autodeterminada, desenvolvimento positivo, qualidade de vida e tempo de vida ${ }^{6}$.

Considerando a importância da promoção de atividades para os idosos institucionalizados, o Programa Qualidade do Viver (QVIVER) proporciona vivências com jogos para idosos desde 2007. A valorização do jogo se dá pelas suas características, pois é visto como uma atividade livre e voluntária, fonte 
de alegria e divertimento exercida dentro de certos limites de tempo e de espaço, tem um fim em si mesmo, suas regras são livremente consentidas, mas absolutamente obrigatórias ${ }^{7}$.

A importância do jogo para o idoso pode ser justificada também por proporcionar o envolvimento dos idosos numa prática que pode ser fonte de diversão e entretenimento e ao mesmo tempo melhorar o seu bem estar físico, psicológico e social ${ }^{8}$. Além disso, durante o jogo os jogadores se surpreendem com os seus próprios desempenhos. E por isso divertem-se. Eles estão entregues ao prazer de brincar são absorvidos pelo jogo. Foram submersos no ambiente lúdico. Esqueceram-se do mundo e de si mesmos?.

Nesse contexto nos questionamos: Como está configurada a capacidade de resiliência em idosos institucionalizadas durante sua participação nas vivências com jogos? Considerando resiliência como a capacidade humana de se adaptar e transformar situações de risco e de vulnerabilidade em potencialidades. Sendo vista, ainda, como um conjunto de processos sociais e intrapsíquicos que possibilitam o desenvolvimento saudável de um indivíduo, mesmo este vivenciando experiências desfavoráveis ${ }^{10-13}$.

Para responder nossa questão problema definimos o objetivo dessa pesquisa: analisar a capacidade de resiliência em idosos residentes numa ILPI que participaram de um programa de práticas corporais com jogos.

\section{MÉTODOS}

Trata-se de uma pesquisa qualitativa desenvolvida em uma ILPI, denominada Associação Promocional do Ancião Dr. João Meira de Menezes (ASPAN), localizada no Município de João Pessoa, capital do Estado da Paraíba. A população da pesquisa, composta por residentes da instituição ASPAN, foi de 99 idosos com idades entre 68 e 108 anos de ambos os gêneros, sendo a amostra de 25 idosos, após triagem que excluiu do estudo àqueles que não possuíam condições físicas e cognitivas mínimas para participação no Programa QVIVER e os que não se dispuseram a participar do estudo de forma voluntária.

Utilizou-se como técnica para coleta de informações a observação participante $^{14}$, durante o desenvolvimento das atividades promovidas pelo projeto de iniciação científica (PIBIC): "O jogo esportivo adaptado e a qualidade de vida em idosos institucionalizados". Esse projeto foi desenvolvido por bolsistas e voluntários participantes do Laboratório de Estudos e Pesquisas em Corporeidade, Cultura e Educação (LEPEC) do Departamento de Educação Física da Universidade Federal da Paraíba (UFPB).

As intervenções ocorreram durante o período de dois meses nas instalações internas da ASPAN. Tais intervenções eram divididas em quatro momentos: a) no primeiro momento, era realizada a leitura de um texto reflexivo (poemas, textos bíblicos e de autoajuda) e uma conversa com os participantes sobre o objetivo da aula, ocorrendo à explicação da mesma; b) o segundo momento era destinado ao alongamento corporal com ênfase à percepção corporal; c) No terceiro momento vivências com jogos, os quais eram adaptados às limitações dos participantes; d) quarto e último momento "Círculo de Cultura", método utilizado para coleta de depoimentos ao final de cada intervenção. Tal estratégia foi desenvolvida por Paulo Freire no contexto da educação de jovens e adultos, que trabalha diretamente com a fala e verbalização do vivido, 
tendo como objetivo a conscientização de exposição de ideias e percepções do grupo sobre a vivência.

Foram realizados três jogos distintos: Passa bola, Boliche e Bocha. Esses jogos foram escolhidos pelo grupo de pesquisa após estudos e conversas a respeito do perfil dos idosos, a intenção foi utilizar jogos que pudessem ser adaptados às peculiaridades dos participantes, pois havia cadeirantes, idosos com deficiência visual e auditiva, além de idosos com perda cognitiva devido a demências. O desafio era incluir todos os idosos que estavam dispostos a participar das aulas.

A princípio escolhemos o Passa bola, pois o jogo se resumia em separar os idosos em duas equipes, cada idoso ficaria sentado formando um círculo por equipe, dentro de cada círculo colocamos cinco bolas, estas deveriam ser pegas uma a uma por um dos componentes da equipe, o primeiro a pegar a bola deveria passá-la para o colega a seu lado que repassaria para os demais, assim a bola seria passada mão a mão por cada participante, o último a pegar a bola deveria colocá-la fora do círculo. O objetivo era colocar as cinco bolas fora do círculo antes da equipe adversária.

O Passa bola foi escolhido por ser um jogo extremamente simples, a intenção da equipe era observar a reação e o envolvimento dos idosos. Por conta do êxito das vivências decidimos propor o Boliche e a Bocha. Estes jogos tem por sua natureza um caráter competitivo. Decidimos manter esse tipo de jogo por percebermos que os idosos estavam sendo estimulados pela competição a participar e se superar a cada jogada. Isso porque, os idosos participantes não eram acostumados com os jogos e muitas vezes mostravam-se desinteressados em praticar uma atividade diferente da sua rotina. Com essa estratégia, estimulando a competição, houve uma adesão maior às atividades propostas.

Para a análise das informações coletadas utilizou-se a Análise de Conteúdo, proposta por Bardin ${ }^{15}$, a qual se caracteriza como um conjunto de técnicas de análise das comunicações para obtenção de indicadores que permitam a inferência de conhecimentos relativos às condições de produção das mensagens por meio de procedimentos sistemáticos e objetivos de descrição do conteúdo dessas mensagens.

Dentre as técnicas de Análise de Conteúdo citadas por Bardin ${ }^{15}$, destacase neste estudo a análise Categorial que funciona por operações de desmembramento do texto em unidades. Essas foram definidas com base nos indicadores para desenvolvimento da resiliência, que de acordo com Sinclair e Walltston $^{16}$, para que se perceba resiliência é necessário existir três características: a) capacidade para enfrentar (perseverança), b) capacidade de continuar a desenvolver-se (superação) e c) capacidade para aumentar as competências (bem-estar). Assim, as categorias de análise foram: Perseverança, Superação e Bem-estar.

Todos os procedimentos descritos foram realizados com o livre consentimento dos pesquisados, cujo projeto de pesquisa foi encaminhado ao Comitê de Ética do Centro de Ciências da Saúde da UFPB por meio da Plataforma Brasil (CAAE $\left.n^{\circ} 10946512.3 .0000 .5188\right)$, recebendo o parecer $n^{\circ} 225.410$ favorável a realização do estudo. 


\section{RESULTADOS}

Participaram do estudo 25 sujeitos residentes da ILPI ASPAN, em sua maioria do gênero feminino (Tabela 1), os quais são beneficiados pelo Programa Qualidade do viver na velhice - UFPB. Esse Programa fundamenta-se na perspectiva da Corporeidade fundamentado na proposta de Gomes-da-Silva ${ }^{9,17,18}$ para a compreensão do envelhecimento, da educação e da saúde.

\begin{tabular}{lc} 
TABELA 1 - Dados Sócio-demográficos & \\
\hline Feminino & $68 \%$ \\
\hline Masculino & $32 \%$ \\
\hline Idade & 86 \\
\hline Média & 8,52 \\
\hline Desvio padrão & \\
\hline Escolaridade & $41 \%$ \\
\hline Alfabetizado & $59 \%$ \\
\hline Não alfabetizado & \\
\hline Estado civil & $22 \%$ \\
\hline Viúvolal & $11 \%$ \\
\hline Casadolal & $61 \%$ \\
\hline Solteirola) & $6 \%$ \\
\hline Separadolal & \\
\hline
\end{tabular}

Conforme o percurso metodológico deste estudo, os resultados foram elucidados à luz da técnica de análise de conteúdo, proposta por Bardin ${ }^{15}$, e exposto sob a forma de falas dos sujeitos participantes, utilizadas de modo que não haja a exposição da identidade dos pesquisados, as quais caracterizam de forma significativa as categorias determinadas para observação nesta pesquisa, a saber: Perseverança, Superação e Bem-estar.

A perseverança, demonstrada pela disposição para experimentar, tentar, arriscar, sem desistir, que emergiram através do jogo, as quais podem ser transpostas para situações cotidianas, pôde ser percebida nas falas expostas no quadro 1. A superação, comumente associada à transposição de obstáculos, mas vista nesta pesquisa como a capacidade de continuar a desenvolver-se, foi evidenciada nas falas do quadro 2 . Os idosos participantes deste estudo, em suas falas, demonstraram também sensação de bem-estar durante a realização do jogo. Esse determinante da resiliência pode ser observado nas falas apresentadas no quadro 3.

QUADRO 1 - Categoria Perseverança

CATEGORIA PERSEVERANÇA

“Eu joguei, mas não acertei. A bola passou direto se fosse com uma calha eu acertava” (IDOSO 01).

"Foi muito bom, eu queria derrubar mais (...)" (IDOSO 02).

“Gostei, foi bom demais, se eu derrubasse tudo, seria uma beleza (...)" (IDOSO 03).

“Todos que estão jogando fazem com prazer, aquele desejo de ganhar aquele jogo" (IDOSO 04).

“Gostei porque eu joguei bem, eu ganhei” (IDOSO 05).

“Eu não entendo muito bem de jogo não, mas deu pra participar um pouco" (IDOSO 06). 
QUADR0 2 - Categoria Superação

\begin{tabular}{|c|}
\hline CATEGORIA SUPERAÇ̃̃O \\
\hline “(...) Eu consegui” (IDOSO 07). \\
\hline “(..) consegui fazer uma bolada” (IDOSO 08). \\
\hline “A gente conseguiu uma grande velocidade, conseguimos passar as bolas com muita velocidade” \\
(IDOSO 09). \\
\hline “Eu consegui fazer aquela bolada e fiquei até surpresa, por que eu sempre estava pensando \\
que não conseguiria fazer nada” (IDOSO 10). \\
\hline “Distrai e tira um pouco da doença. Naquela hora (do jogo) isso é necessário. Naquele momento \\
passa, embora depois volte que é uma coisa natural” (IDOSO 11). \\
\hline “Eu achei bom porque é uma diversão né, agente já tá aqui preso quer se divertir e ainda mais \\
num tem nada pra divertir" (IDOSO 12) \\
"Rapaz no dia de hoje mesmo tá tudo bom, gostei muito, fiz mais ponto de que na semana passada” \\
(IDOSO 13).
\end{tabular}

QUADRO 3 - Categoria Bem-estar

\section{CATEGORIA BEM-ESTAR}

"Eu estava com dor nas costas, e agora a dor parou, eu mandei para o espaço" (IDOSO 14).

"Eu me sinto uma menina de quatorze anos" (IDOSO 15).

"Foi bom meu filho, foi uma alegria muito grande, porque eu tava toda dolorida e velha e tô hoje bem melhor" (IDOSO 16)

"Porque é uma brincadeira que anima agente e toma conta da gente" (IDOSO 17)

“(..) sai um pouquinho da monotonia, cansa um pouquinho aqui, é bom!!! Trás pessoas de fora e são horas diferente"(IDOSOS 18).

“Todo mundo ficou alegre e satisfeito igual a mim" (IDOSO 19).

“(..) foi bom, tou um pouco doente. Me senti bem porque o jogo é bom” (IDOSO 20).

“Me senti feliz meu filho, muito feliz (...)"(IDOSO 21).

“Não tinha nenhuma doença no meu corpo na hora do arremesso. Pra mim eu tava boinha" (IDOSO 22).

\section{DISCUSSÃO}

O estudo observou que o jogo pode ser mencionado como um recurso importante para composição de intervenções que tenham o idoso como foco de atenção, sobretudo, no que diz respeito ao idoso em situação de vulnerabilidade, exclusão e estigma social como é o caso do idoso institucionalizado.

Segundo Gomes-da-Silva ${ }^{9}$ o jogo é tido como uma maneira de reinvenção do real e com isso favorece significado à existência humana. Isto é observado, nas expressões de vivacidade do jogador. Por mais variados que sejam os jogos, há uma semelhança que os define como relevante, que é o ganhar ou perder, a tentativa constante de superação, a integração, a socialização, as aptidões físicas, cognitivas e, principalmente, a vitalidade, que é nítido naquele que joga com ânimo, com vigor. Essas características, além de serem expressas nas falas dos idosos, sujeitos sociais desse estudo, também foram claramente identificadas durante a execução das atividades ao longo da realização da pesquisa.

Os sujeitos pesquisados e participantes da intervenção, proposta nesse estudo, são em sua maioria do gênero feminino. Tal fenômeno pode ser denominado de feminização da velhice ${ }^{19}$ e tem sido percebido como uma tendência em estudos que envolvem população de idosos. Essa predominância tem sido atribuída, entre outros fatores, a menor exposição a fatores de risco, menor 
prevalência de tabagismo e álcool e uma maior cobertura e políticas públicas voltadas à saúde da mulher ${ }^{20,21}$.

Esse fenômeno pode ser constatado, inclusive, nos programas ou grupos de convivência destinados a idosos, no qual a presença das mulheres é algo facilmente observável. O grupo pesquisado é participante de uma proposta, no qual o rol de atividades é fundamentada na perspectiva da corporeidade apresentada por Gomes-da-Silva ${ }^{17,18}$.

Como produto desse embasamento teórico as intervenções têm buscado ampliar a rede de apoio, estimular a capacidade de compartilhar emoções em grupo, desenvolver o diálogo como veículo das inter-relações sociais e da intimidade pessoal, melhorar a expressividade, produzir desinibições, de forma a promover um melhor estado de saúde mental, física e social, que vão para além das medidas de aptidão física que, geralmente, são associadas aos objetivos das intervenções na área de educação física ${ }^{22-23}$.

Os programas destinados a idosos, sob essa ótica, são importantes, pois promove no idoso, o desenvolvimento de atitudes de superação de dificuldades, de oportunidades de busca de seu bem-estar e de vitória sobre os desafios impostos pelas limitações peculiares da idade e pela sociedade, no que diz respeito aos estereótipos e preconceitos ${ }^{23}$.

Tais resultados são inerentes ao desenvolvimento da resiliência, na medida em que essa é vista como um processo que abrange aspectos individuais e sociais, como o fortalecimento dos traços positivos e sua relação no meio comunitário e/ou no grupo social em que convive ${ }^{24}$.

Assim, torna-se notório que o planejamento de intervenções em ILPI deve oportunizar mudanças adaptativas que proporcionem equilíbrio entre ganhos e perdas inerentes ao processo de envelhecimento. Para tanto, as atividades propostas devem potencializar o enfrentamento de situações adversas, de modo a emergir os sentimentos de perseverança, superação e bem-estar, considerados indicadores e condicionantes para o desenvolvimento da resiliência ${ }^{16}$.

Favorecer essas situações em ILPI torna-se importante meio para o desenvolvimento da resiliência, já que, muitas vezes, parte dessas instituições possui um perfil assistencialista, no qual prestar cuidados aos idosos resume-se a oferecer abrigo e alimentação. Além disso, o processo de institucionalização traz consequências particulares para o indivíduo, uma vez que as relações interpessoais no interior das instituições tendem a ocorrer estritamente entre a pessoa institucionalizada e seus pares com as mesmas características em uma rotina, geralmente, pouco desafiadora ${ }^{25}$.

Partindo dessa premissa, considera-se a institucionalização uma das situações estressantes que levam o sujeito a passar por transformações que podem levá-lo à perda de identidade, de liberdade, de autoestima, ao estado de solidão e muitas vezes de recusa da própria vida, o que justifica a alta prevalência de doenças mentais nos asilos ${ }^{25}$.

A manutenção do comportamento resiliente no idoso institucionalizado exige uma intervenção bem planejada dos profissionais responsáveis pela atenção aos residentes. Essa intervenção deve prevê metodologias que contemplem atividades, no qual o idoso seja visto de forma holística, ao contrário de analisá-lo estritamente sob sua condição de saúde física e biológica.

A concepção holística, no âmbito das ações em saúde, está relacionada com uma compreensão ampliada do ser humano, no qual as intervenções voltadas 
ao mesmo ocorrem numa abordagem integrada, de modo a considerar o ser vivo com um todo, em suas dimensões biopsicossociais ${ }^{26,27}$.

A partir das falas pudemos observar a presença da perseverança, durante o jogo. Os jogadores demonstraram disposição para solucionar dificuldades vividas como, por exemplo, com a possível utilização de um equipamento para auxiliá-lo no jogo de bocha, a calha. Como também, estímulo para executar mais uma jogada acreditando que iam obter êxito. A sensação de ter ganhado ou a expectativa que poderiam ganhar também esteve presente nas falas.

Essa perseverança foi estimulada pelo jogo, pois como afirma Gomes-daSilva ${ }^{9}$, os jogadores são absorvidos pelo jogo, estão entregues ao prazer de jogar, estão submergidos no ambiente lúdico. Essa vivência com jogos pode estimular uma nova maneira de ver sua realidade. Muitos desses idosos não têm mais perspectivas de futuro, porém no momento do jogo surge uma expectativa não só que haverá o próximo jogo, mas acreditam que vão melhorar.

A superação comumente associada à transposição de obstáculos, mas vista nesta pesquisa como a capacidade de continuar, a desenvolver-se, foi observada a partir da autoafirmação de ter conseguido executar determinada jogada ou alcançado um objetivo do jogo e ao valorizar a vivência.

Como afirma Gomes-da-Silva9 durante o jogo os jogadores se surpreendem com os seus próprios desempenhos, e percebemos que ao se surpreenderem são estimulados a continuar jogando, essa atitude foi evidenciada também nas observações das aulas, pois ao ser finalizada muitos idosos pediam para jogar mais uma vez, para ter mais uma chance. Ao ser permitido eles faziam várias tentativas, chegaram até a fazer fila aguardando sua vez.

Os idosos participantes deste estudo, em suas falas, demonstraram também sensação de bem-estar. Durante a realização do jogo eles se esqueceram de suas dores, sentiram-se rejuvenescidos, alegres e felizes. $\mathrm{O}$ jogo favorece o bem-estar por ser uma atividade em grupo, pois facilita a maior interação interpessoal, além de contribuir para o sentimento de significado pessoal ${ }^{6}$. Além disso, o jogo estimula a diversão, o prazer melhora o bem-estar físico, psicológico e social ${ }^{8}$.

A partir dessa pesquisa podemos observar a importância do jogo para pessoas idosas. Durante muitos anos a Educação Física tratou o jogo como recurso para crianças, mas, hoje, mesmo sendo escasso, têm surgido pesquisas utilizando o jogo para intervenções com adultos mais velhos ${ }^{8,28-30}$.

Em um levantamento encontramos estudos que utilizavam vídeo games ativos para idosos ${ }^{28}$. O número de pesquisas com vídeo game ativo vem crescendo, embora concordamos com Mubin e colaboradores ${ }^{8}$ que em muitos casos a prática com vídeo games não é viável para os idosos. No caso dos sujeitos da nossa pesquisa, não haveria recursos financeiros, além da barreira existente por conta da baixa escolaridade do grupo.

Há pesquisas que utilizam jogos educativos para os idosos aprenderem sobre suas doenças ${ }^{29}$, como também, pesquisas que utilizam o jogo a fim de estimularem as funções executivas ${ }^{30}$. Com as buscas, percebemos que há uma tendência de valorização do jogo, contundo, havendo a necessidade de mais pesquisas com a população idosa. Pois, tem-se percebido que há muitas possibilidades de intervenção com jogos seja para reabilitação, aprendizado, lazer e saúde.

Entretanto, percebemos ainda uma lacuna em relação a pesquisas que abordem a análise da resiliência em vivências com jogos, como também, a 
análise do jogo como meio de estimular um comportamento resiliente perante a vida de pessoas idosas.

Os achados do estudo permitiram concluir que o jogo estimulou a capacidade de resiliência nos idosos participantes da pesquisa. Encontramos falas que indicaram Perseverança, Superação e Bem-estar. Sabemos que as afirmações dos idosos não configuram, necessariamente, um comportamento resiliente no cotidiano dessas pessoas, mas, acreditamos, a partir das falas, que o estímulo proporcionado pelo jogo pode influenciar a maneira de proceder em suas vidas.

Assim, identificamos a necessidade de mais estudos que analisem a potencialidade do jogo como uma estratégia para a promoção da resiliência em idosos. Percebe-se a resiliência como um objetivo contemporâneo em saúde, que propõe uma análise mais holística e subjetiva de mensuração de qualidade de vida e bem-estar. Dessa forma, torna-se importante todas as contribuições sobre as descobertas das especificidades quanto à promoção da resiliência, já que esta abrange desde aspectos individuais a aspectos do meio social para seu alcance.

\section{REFERÊNCIAS}

1. Papaléo Netto M. O estudo da velhice: histórico, definição do campo e termos básicos. In: Freitas EV, Py L, Cançado FAX, Doll J, Gorzoni ML (eds). Tratado de Geriatria e Gerontologia. $2^{\mathrm{a}}$ ed. Rio de Janeiro: Guanabara Koogan;2006.p. 8-10.

2. Silva JAC, Almeida MHM. Orientações políticas e prática profissional em instituições de longa permanência para idosos. Estud. interdiscip. envelhec. 2013; 18(1): 119-35.

3. Brasileiro MDS, Figueiredo Júnior JM. Educação Física e instituições para idosos: novas perspectivas de prevenção. In: Afonso MR, Cavalli AS, Campos ALP (orgs). Trabalhando com a terceira idade: estudos e pesquisas. Pelotas: Ed. UFPEL;2011.p. 67-82.

4. Duca GFD, Silva MC, Silva SG, Nahas MV, Hallal PC. Incapacidade funcional em idosos institucionalizados. Rev Bras Ativ Fis e Saúde. 2011;16(2):520-3.

5. Meléndez-Moral JC, Charco-Ruiz L, Mayordomo-Rodríguez T, Sales-Galán A. Effects of a reminiscense program among institutionalized elderly adults. Psicothema (Oviedo). 2013; 25(3);319-23.

6. Deps VLA. Ocupação do tempo livre sob a ótica de idosos residentes em instituições: análise de uma experiência. In: Neri AL (org). Qualidade de vida e idade madura. $4^{\mathrm{a}}$ ed. Campinas, SP: Papirus, 2002.

7. Huizinga, J. Homo ludens: o jogo como elemento da cultura. São Paulo: Perspectiva, 2010.

8. Mubin O, Shahid S, Mahmud A. Walk 2 Win: Towards Designing a Mobile Game for Elderly's Social Engagement. The 22nd British HCI Group Annual Conference. 2008; 2;11-4.

9. Gomes-da-Silva PN. O jogo da cultura e a cultura do jogo: por uma semiótica da corporeidade. João Pessoa: Editora Universitária da UFPB, 2011.

10. Fergus S, Zimmerman MA. Adolescent resilience: a framework for understanding healthy development in the face of risk. Annu Rev Public Health. 2005; 26:3 99-119.

11. Leipold B, Greve W. Resilience: a conceptual bridge between coping and development. Eur Psychol. 2009;14(1):40-50.

12. Wright M, Masten A. Resilience processes in development: Fostering positive adaptation in the context of adversity. In: Goldstein S, Brooks R, Editores. Resilience in children. Nova York: Klunwer Academic/Plenum Publishers, 2005.

13. Pinheiro DPN. A resiliência em discussão. Psicol. estud. 2004;9(1):67-75.

14. Flick U. Introdução à pesquisa qualitativa. $3^{\text {a }}$ ed. Porto Alegre: Artmed, 2009.

15. Bardin L. Análise de conteúdo. Lisboa: Edições 70, 2011.

16. Sinclair VG, Wallston KA. The development and psychometric evaluation of brief resilient coping scale. Assessment. 2004;11(1):94-101. 
17. Gomes-da-Silva PN. Entrevista com Pierre Normando Gomes da Silva. In: Gonsalves E, Forastieri R, Lima S (eds). Trajetórias entrelaçadas. João Pessoa: Scanner, 2007.

18. Gomes-da-Silva PN. A corporeidade do movimento: por uma análise existencial das práticas corporais. In: Hermida JF, Zoboli F. (orgs). Corporeidade e educação. João Pessoa: Editora Universitária da UFPB, 2012.

19. Salgado CDS. Mulher idosa: a feminização da velhice. Estud. interdiscip. envelhec. 2002;4: 7-19.

20. Coelho Filho JM, Ramos LR. Epidemiologia do envelhecimento no nordeste do Brasil: resultados de inquérito domiciliar. Rev Saude Publica. 1999;33(5):445-53.

21. Ferrreira CL, Santos LMO, Maia EC. Resiliência em idosos atendidos na Rede de Atenção Básica de Saúde em município do nordeste brasileiro. Rev Esc Enferm USP. 2012;46(2):328-34.

22. Figueiredo Júnior JM, Gomes-da-Silva PN. Expressividade e sensorialidade: por uma metodologia da educação física na saúde de idosos. Rev Bras Ativ Fis e Saúde. 2011;16(2):172-6.

23. Figueiredo Júnior JM, Ribeiro CRF, Gomes-da-Silva PN. Resultados de um programa de promoção da saúde sob a expressividade e sensorialidade em idosos. Estud. interdiscip. envelhec. 2011; 16(2):185-98.

24. Cabral SA, Levandowski DC. Resiliência e psicanálise: aspectos teóricos e possibilidades de investigação. Rev Latinoam Psicopat Fund. 2013;16(1):42-55.

25. Tada INC, Bisconsin CF, Freitas DC, Passos ET, Nascimento, GT, Castro, JS, et al. Intervenção psicológica com pessoas com deficiência em situação asilar. RPCP. 2012;32(3):744-53.

26. Chalermsri C, Paisansudhi S, Kantachuvesiri P, Pramyothin P, Washirasaksiri C, Srivanichakorn $W$, et al. The effectiveness of holistic diabetic management between Siriraj Continuity of Care clinic and medical out-patient department. J Med Assoc Thai. 2014; 97(3): 197-205.

27. Hilbers J, Lewis C. Complementary health therapies: moving towards an integrated health model. Collegian. 2013; 20(1): 51-60.

28. Maillot P, Perrot A, Hartley A. Running Head Exergames: Effects of Interactive Physical-Activity Videogame Training on Physical and Cognitive Function in Older Adults. Psychology and Aging. 2012;27(3): 589-600.

29. Torres H C, Hortale VA, Schall V. Experience with games in operative groups as part of health education for diabetics. Cad Saude Publica. 2003;19(4): 1039-47.

30. Lima AMA, Hirata FCC, Bruin GS, Mota RMS, Bruin VM. The influence of playing a non-reward game on motor ability and executive function in Parkinson's disease. Behav Neurol. 2012;25(2): 119-25.

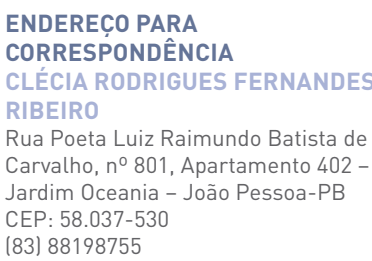

RECEBIDO 21/02/2013 REVISADO 29/07/2014 APROVADO 29/07/2014 